Article

\title{
Grain-Boundary-Induced Alignment of Block Copolymer Thin Films
}

\author{
Steven Gottlieb, Marta Fernández-Regúlez, Matteo Lorenzoni, Laura Evangelio and \\ Francesc Perez-Murano * (D)
}

Instituto de Microelectrónica de Barcelona (IMB-CNM, CSIC), Bellaterra, 08193 Barcelona, Spain; stgottl@googlemail.com (S.G.); marta.fernandez@imb-cnm.csic.es (M.F.-R.); matteo.lorenzoni@gmail.com (M.L.); lauraevangelioaraujo@gmail.com (L.E.)

* Correspondence: francesc.perez@imb-cnm.csic.es; Tel.: +34-935-94-77-00 (ext. 2113)

Received: 3 December 2019; Accepted: 30 December 2019; Published: 4 January 2020

\begin{abstract}
We present and discuss the capability of grain boundaries to induce order in block copolymer thin films between horizontally and vertically assembled block copolymer grains. The system we use as a proof of principle is a thermally annealed $23.4 \mathrm{~nm}$ full-pitch lamellar Polystyrene-block-polymethylmetacrylate (PS-b-PMMA) di-block copolymer. In this paper, grain-boundary-induced alignment is achieved by the mechanical removal of the neutral brush layer via atomic force microscopy (AFM). The concept is also confirmed by a mask-less e-beam direct writing process. An elongated grain of vertically aligned lamellae is trapped between two grains of horizontally aligned lamellae. This configuration leads to the formation of $90^{\circ}$ twist grain boundaries. The features maintain their orientation on a characteristic length scale, which is described by the material's correlation length $\xi$. As a result of an energy minimization process, the block copolymer domains in the vertically aligned grain orient perpendicularly to the grain boundary. The energy-minimizing feature is the grain boundary itself. The width of the manipulated area (e.g., the horizontally aligned grain) does not represent a critical process parameter.
\end{abstract}

Keywords: nanolithography; block copolymers; directed self-assembly; grain boundaries; AFM; mechanical removal

\section{Introduction}

Block copolymers consist of two or more chemically different polymer chains covalently bonded together [1]. Driven by the repulsive force between chemically different molecules, the chains self-assemble in periodic structures, with characteristic size between few nanometers and few tens of nanometers. These periodic structures can be used as high resolution, bottom-up templates for nanofabrication processes, as for example bit patterned media for hard disk drives [2-4], finFETs [5], and contact holes [6].

A single-crystalline self-assembly morphology (e.g., perfect long-range order) cannot be achieved during the annealing of block copolymer thin films, despite of the fact that single-crystalline morphologies represent the minimal achievable free energy [7]. The formation of a rich variety of defects leads to polycrystalline morphologies and consequently represents limiting factor for the use of block copolymer self-assembly in many applications requiring a low defect density. As of now, this insufficiently low defect density is one of the main problems for the integration of block copolymer lithography in high volume manufacturing (HVM) processes [8].

Chemical and surface patterns defined by top-down lithography are usually used to introduce long-range order and placement accuracy in block copolymer thin films. These patterns are referred to as guiding patterns. The approach of directing the self-assembly of block copolymers by means of topographical patterns is referred to as graphoepitaxy. This principle has been successfully employed 
by a number of groups, as reported in different works in the last years [9-14]. Very low defect densities can be obtained when the width of the confining trench is exactly or close to an integer multiple of the natural pitch of the block copolymer [15-17]. A suitable guiding pattern design permits it to direct the self-assembly of block copolymers in device-oriented features $[5,18]$, induce long-range order in sub-10 nm half-pitch block copolymers [19] and sub-5 nm half-pitch liquid crystals [20].

The chemoepitaxy approach relies on the introduction of chemical patterns into an underlying polymeric substrate. The orientation of block copolymers can be successfully controlled by the use of self-assembled monolayers [21] and crosslinked polymer mats [22] as underlayers. Common ways to manipulate the surface free energy of a Polystyrene-random-polymethylmetacrylate (PS-r-PMMA) brush layer is to combine a lithography step with the exposure to UV light [23] or to oxygen plasma [24]. The critical dimension of the guiding pattern features has to correspond to $(n-0.5)$ times the block copolymer pitch $[25,26]$ with $n$ being a positive integer.

In contrast to the well-explored approaches of graphoepitaxy and chemoepitaxy, there are only few works that study the use of grain boundaries to introduce order in block copolymer thin films. On the other side, the shape of grain boundaries in block copolymers and the energy minimization process associated to their formation in lamel lar block copolymers have been studied quite extensively for bulk materials, and reported in excellent experimental [27-30] and theoretical [31-34] works. A brief review of grain boundary morphologies in block copolymers can be found in Appendix A.1.

The few existing works on $90^{\circ}$ twist grain boundaries in relation with block copolymer thin films include, for example, experiments with two chemically patterned plates [35], where the grain boundaries are formed parallel to the substrate, and with soft graphoepitaxy, where $90^{\circ}$ twist grain boundaries have been observed for film thicknesses significantly larger than the guiding pattern feature height [36]. The ordering of block copolymers perpendicular to grain boundaries has recently also been identified as a metastable state in the chemoepitaxial alignment of block copolymers [37] and referred to as "stitch morphology". Interestingly, in reference [38], the authors are capable of directing the self-assembly of block copolymers by the creation of structures under the formation of $90^{\circ}$ tilt grain boundaries by mixing the pure block copolymer with a determined ratio of its constituent homopolymers, although it does not represent the energetically most favorable grain boundary morphology for pure block copolymer films [39]. Chemoepitaxy has been used to direct block copolymers into device-oriented features [40]. Despite of few isolated examples, grain boundaries have not been considered as order-inducing features in the directed self-assembly of block copolymers.

In this work, we trap one grain of vertically self-assembled block copolymers between two elongated grains of horizontally aligned block copolymers (see Figure 1a). With vertically self-assembled block copolymers we refer to areas where the lamellae are oriented perpendicular with respect to the substrate, while they are oriented parallel to the substrate in case of the horizontal self-assembly morphology. The driving force of the directed self-assembly in this set-up originates from $90^{\circ}$ twist grain boundaries formed on both sides of the trapped vertically oriented grain. These naturally formed grain boundaries are the reason any other guiding pattern features are redundant.

We present grain-boundary-induced alignment (GBIA) as an interesting complementary technique to direct the self-assembly of block copolymers, because it represents a versatile method to align the material on lengths up to its correlation length $\xi$. The correlation length $\xi$ characterizes the length range where the self-assembly of block copolymers can be successfully directed by grain-boundary-induced alignment. The parameter $\xi$ is inversely proportional to the defect density in the film [41] in fingerprint pattern. Due to the absence of guiding patterns in a stricter sense, grain-boundary-induced alignment does not increase the mean grain size of the material, but rather orients the grains perpendicular to the formed grain boundaries.

\section{Results}

The fabrication of aligned block copolymer patterns via (GBIA) has been realized using two different nano-patterning methods: (i) Atomic force microscopy (AFM) mechanical removal 
(m-AFM) and (ii) direct e-beam exposure of the underlying neutral brush layer. In block copolymer lithography, brush layers are commonly used to control the free energy between the substrate and the block copolymer thin film. Most commonly, the brush layer is a random copolymer consisting of the same two components as the used block copolymer. In case the random copolymer (here: Polystyrene-random-polymethylmetacrylate $(P S-r-P M M A))$ consists of the same or similar volume fraction as the block copolymer (here: Polystyrene-block-polymethylmetacrylate (PS-b-PMMA)), the surface is wetted by both two block copolymer components. A brush layer that favors vertical self-assembly in block copolymers is referred to as neutral brush. In the specific case of a lamellar block copolymer as used in this work, a neutral brush leads to vertically standing block copolymer domains. The two workflow variations are presented in the two following sub-sections and they are depicted in Figure 1a. As we will explain in the following sections, the selective treatment of the brush layer is used to manipulate the interface energy between the block copolymer and the substrate in such a way that we are capable of changing the self-assembly mode of the block copolymer from vertical to horizontal.
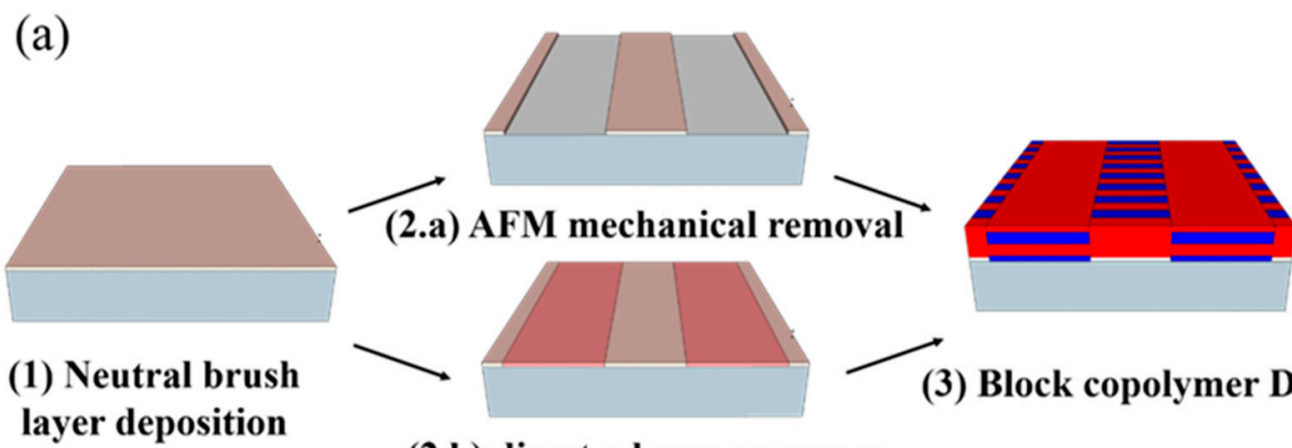

(3) Block copolymer DSA

(2.b) direct e-beam exposure

(b)

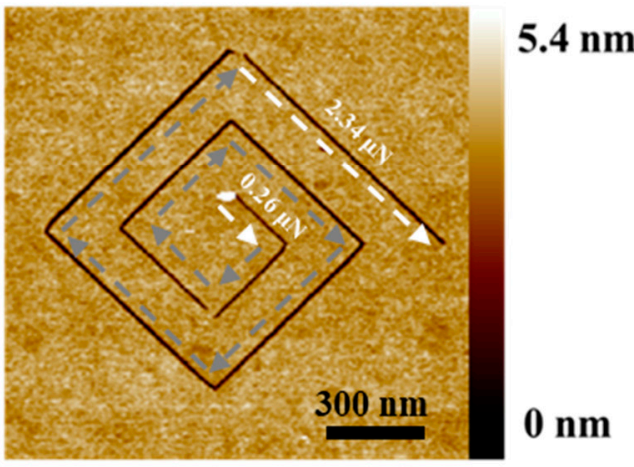

(c)

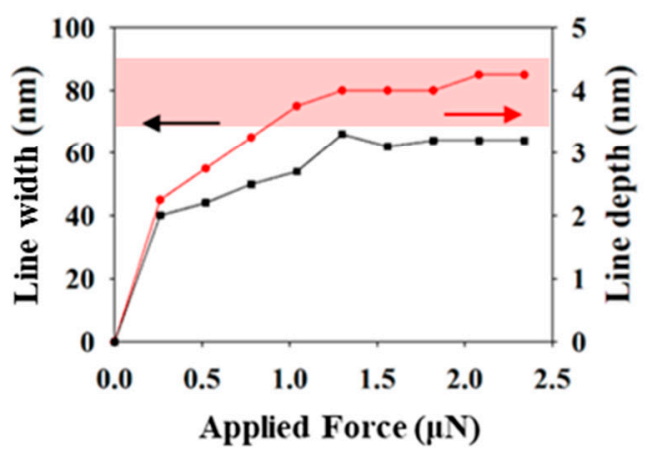

Figure 1. Grain boundary induced alignment principle and work-flow. (a) Work-flow to direct the self-assembly of block copolymers by grain-boundary-induced alignment; (b) Force-dependence of the mechanical brush removal while successively increasing the contact force from $0.26 \mu \mathrm{N}$ to $2.34 \mu \mathrm{N}$ from the inside to the outside of the spiral. (c) Linewidth (y-axis on left hand side) and line depth (y-axis on right hand side) as a function of the applied force extracted from the pattern shown in (b).

\subsection{Alignment Induced via Mechanical AFM (m-AFM)}

As depicted in Figure 1a, sketch (2.a), the fabrication of contact pads in the m-AFM approach relies on the mechanical removal of the neutral brush layer using an AFM tip. The AFM height image depicted in Figure $1 \mathrm{~b}$ represents a force test to determine the most suitable contact force for the mechanical removal of the neutral brush layer. Here, the contact force has been increased from $0.26 \mu \mathrm{N}$ to $2.34 \mu \mathrm{N}$ in steps of $0.26 \mu \mathrm{N}$ each segment, where the lowest contact force is applied for the innermost segment of the spiral (see Figure 1b). Based on this experiment, we determine $1.04 \mu \mathrm{N}$ as the minimum required contact force to ensure the complete removal of the neutral brush layer down to 
the substrate (see Figure 1c), because we observe that both line width and line depth enter in a plateau regime where they are no longer a function of the applied force, i.e., further increasing the contact force further does not lead to a larger indentation depth.

For the first set of experiments, we have removed the neutral brush layer in areas of $500 \mathrm{~nm} \times 5 \mu \mathrm{m}$ (Figure 2a). The width of the areas has been chosen so that the resulting structures have a reasonable size for a later characterization. The mechanical removal uncovers the underlying silicon substrate, which is preferentially wetted by PMMA. During the self-assembly process, when the block copolymer is heated above its glass transition temperature, the formation of horizontal lamellae is induced in these areas.For block copolymer film thicknesses in the range of $\mathrm{L}_{0}$, (where $\mathrm{L}_{0}$ is the natural full pitch of the lamellar block copolymer), the top material is thus PMMA. On the other hand, the top-layer consists of $P S$ when the film thickness is in the range of $1.5 \mathrm{~L}_{0}$.

As the m-AFM technique is physically displaces the random polymer brush, pile-ups are formed adjacent to the borders of the modified areas. In order to remove pile-ups of removed random copolymer and to be capable of analyzing the sample appropriately via AFM, the sample undergoes a Propylene glycol methyl ether acetate (PGMEA) rinsing step before taking the AFM height image in Figure 2a. The distance $d$ between the two modified zones, as depicted in Figure 2a, is $300 \mathrm{~nm}$. The height step of approximately $7 \mathrm{~nm}$ corresponds to the height of the random copolymer layer, which has been entirely removed in the two recessed, modified areas. The two recessed areas is what we refer to as guiding pattern for this application. The result of the directed self-assembly on these guiding patterns is depicted in an AFM height image (Figure 2b) and phase image (Figure 2c). Profiles revealing the sample topography perpendicular to the modified areas before and after the directed self-assembly step are presented in Figure 2e,f. The vertically aligned block copolymer structures have a notably shallower (and inversed) topography of around $2 \mathrm{~nm}$. The block copolymer in the trapped grain adapts its thickness to the height of the adjacent horizontally self-assembled grains. Additional information concerning the analysis of effect is presented in Appendix A.2.

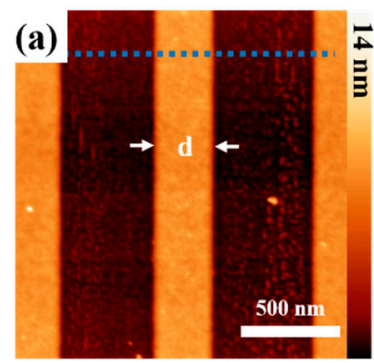

(e)

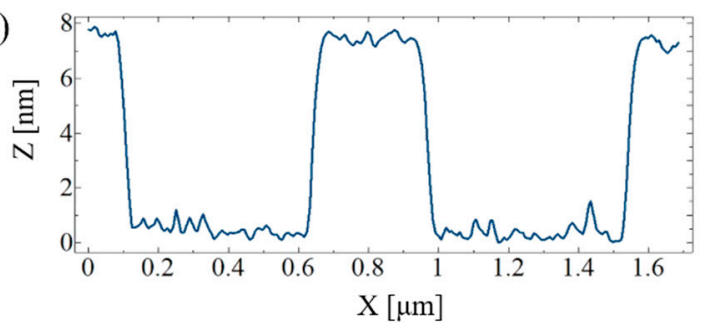

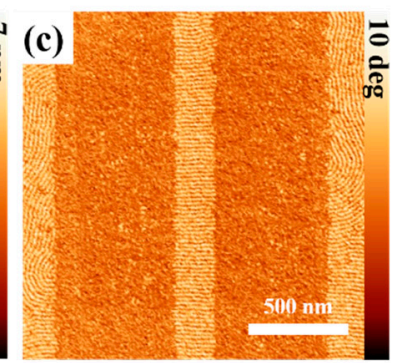

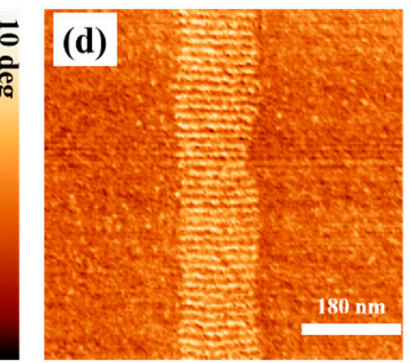

(f)

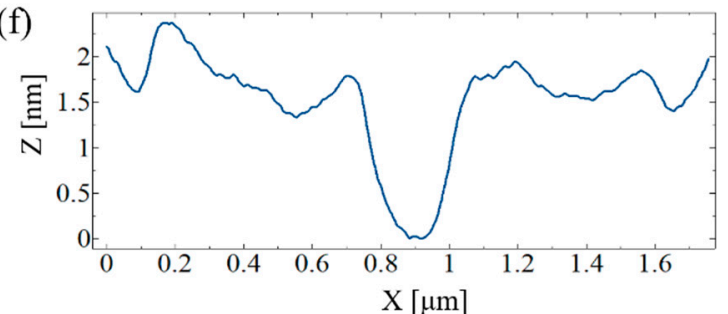

Figure 2. Results of grain-boundary-induced alignment via atomic force microscopy (AFM) mechanical removal. (a) AFM height image of guiding pattern with two areas treated by AFM mechanical removal (m-AFM) without brush layer (corresponds to sketch 2.a in Figure 1); (b) AFM height image of directed self-assembly (DSA) on area depicted in (a); (c) AFM phase image taken simultaneously to image (b), showing the self-assembly in horizontal (wide stripes) and vertical (narrow stripes) lamellae; (d) Zoom-in the central stripe of the AFM phase image of (c); (e) single line profile along blue dashed line in (a); (f) average height profile (i.e., average of all line scans) as indicated by the box in (b). 


\subsection{Alignment Induced via Electron Beam Direct Exposure}

The second case is the surface modification by an exposure to an electron beam, where we make use of the modification of the neutral brush layer due to interaction with charged particles. As explained by Evangelio et al. [26], high electron beam exposure doses (e.g., $256 \mathrm{mC} / \mathrm{cm}^{2}$ ) cause a change in the surface free energy of $P S-r-P M M A$ and convert the nominally neutral brush layer into a brush layer that is preferentially wetted by $P M M A$. As explained before, this effect, in turn leads to horizontal self-assembly similar to the one observed after the removal of the neutral brush layer, but dispensing with the physical removal of material. Figure 3 shows the results of self-assembly in the direct vicinity of a $65 \mathrm{~nm}$ wide line (Figure 3a) and a $65 \mathrm{~nm}$ wide pristine area Figure $3 \mathrm{~b}$. The orientation of the block copolymer perpendicular to the grain boundary is explained by the energy minimization inside the grain boundary and occurs as a direct consequence of the formation of $90^{\circ}$ twist grain boundaries.

(a)

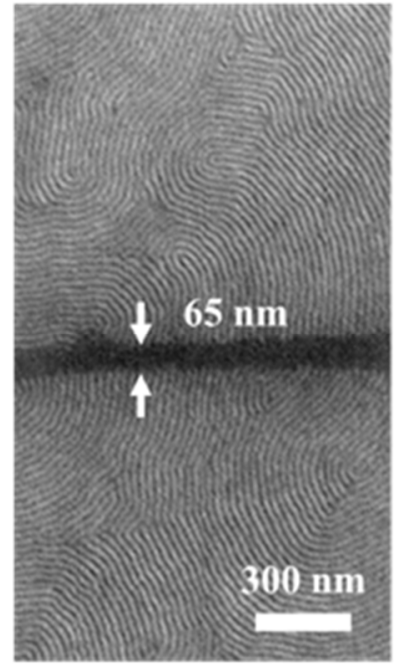

(b)

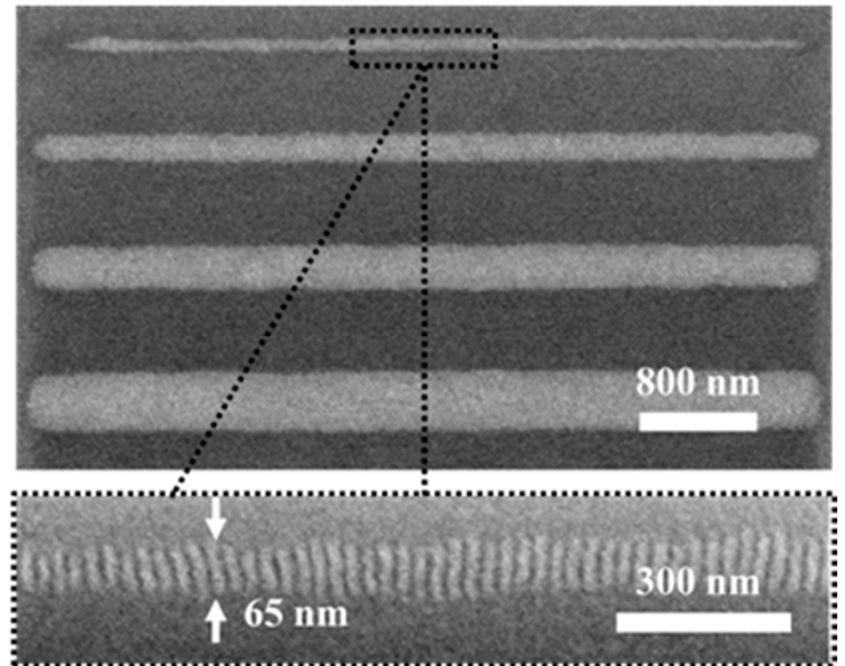

Figure 3. Results of grain-boundary-induced alignment obtained by electron beam direct writing. (a) Horizontal self-assembly on a $65 \mathrm{~nm}$ wide stripe; (b) vertical self-assembly (e.g., grain-boundary-induced alignment) on stripes of different widths with a minimum of $65 \mathrm{~nm}$.

\subsection{Results of Pattern Transfer of Directed Features into Silicon}

To make use of grain-boundary-induced alignment for lithography applications, it is important to be capable of transferring the defined structures into silicon. As it is depicted in Figure 4, the pattern transfer process consists of two steps. After the guiding pattern fabrication (see Figure 4a) and the self-assembly (see Figure $4 \mathrm{~b}$ ), it is necessary to remove the PMMA, so that the remaining PS can serve as an etch mask. This process step is displayed in Figure 4c, where the bright lines correspond to $P S$ features and the dark lines correspond to the voids created by removed PMMA. The PMMA removal can effectively be done using various oxygen-containing gas mixtures, such as $\mathrm{Ar} / \mathrm{O}_{2}$ or $\mathrm{CHF} / \mathrm{O}_{2}$ (see Materials and Methods part of this paper for more information). PS, in turn, is relatively more inert than PMMA towards oxygen-containing plasma etch processes, enabling an etch selectivity around 3.

Secondly, we use the remaining PS template as an etch mask to transfer the defined features into silicon. The result of the pattern transfer of few nm depth into silicon is depicted in Figure $4 \mathrm{~d}$. A great advantage for the fabrication of devices with this technique is that the horizontally aligned block copolymers serve as an etch mask and preclude the chemical attack of $\mathrm{Si}$ in this area. If the process is conducted on a Silicon-on-Insulator (SOI) wafer, these areas can subsequently be used as electrical contacts, because the silicon below remains intact. This work-flow may represent a simple method for the fabrication of dense nanowire arrays for nanoelectronic devices. 
(a)

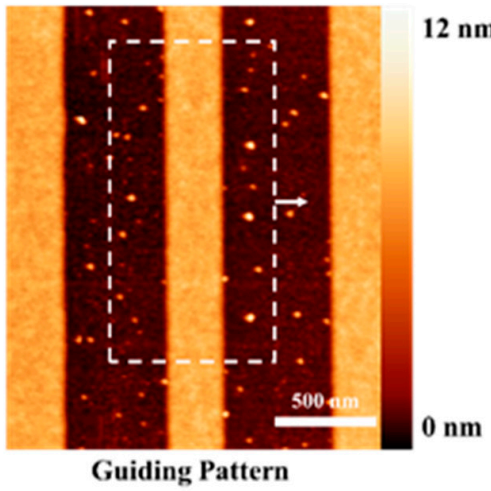

(b)

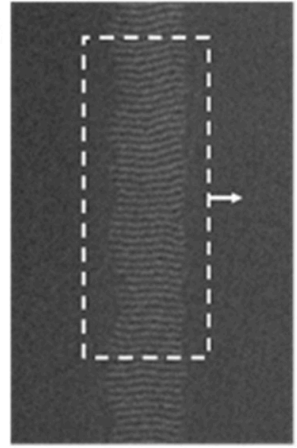

Directed Self-Assembly (c)

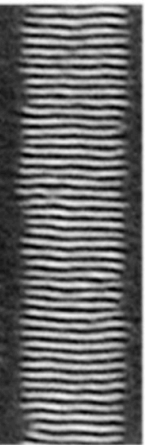

PS mask (d)

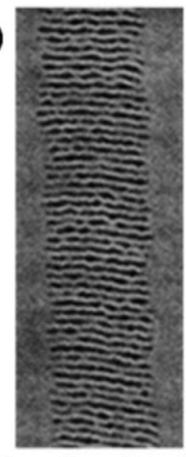

Transferred to $\mathrm{Si}$

Figure 4. Micrographs of different fabrication stages in the pattern transfer process. (a) AFM image of m-AFM treated area for grain-boundary-induced alignment; (b) DSA of block copolymers on the presented guiding pattern, while the excerpt corresponds to area surrounded by dashed line in (a); (c) PS etch mask after selective removal of PMMA via Reactive Ion Etching (RIE) (area corresponds to white dashed line in (b)); (d) pattern transferred into silicon.

\section{Discussion}

\subsection{Surface Energy Modification by m-AFM}

As the surface energy modification of a polymeric brush layer by direct e-beam exposure has been presented elsewhere [26], in this section we will focus on the surface energy modification induced by the m-AFM step.

The analysis of the wetting behavior of a homopolymer blend consisting of the components of the block copolymer can serve as a qualitative test for the surface energy in micrometric areas $[26,42]$. Here, we use this technique to qualitatively understand the surface energy by observing the behavior of a PS/PMMA blend in the modified and in the non-modified area. Phase separation of PS and PMMA is induced by the annealing of the film at $230^{\circ} \mathrm{C}$ for few minutes. To be capable of distinguishing the two polymers more easily in the SEM images, we subjected the sample to an $18 \mathrm{~s}$ oxygen plasma treatment at $500 \mathrm{~W}$ source power. Due to the higher etch resistivity of $P S$ with respect to $P M M A$, we expect the $P M M A$ droplets to be recessed in height. The results are depicted in Figure 5. Figure 5a shows the behavior of the polymer blend in the close vicinity of a $5 \mu \mathrm{m} \times 50 \mu \mathrm{m}$ stripes, where the neutral brush layer has been removed by means of m-AFM. In Figure $5 b$ we observe a behavioral difference of the polymer blend between the modified area and the pristine area in more detail.

(a)

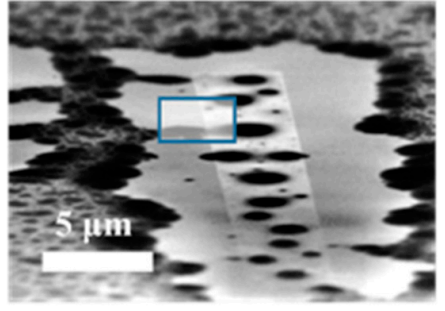

(c)
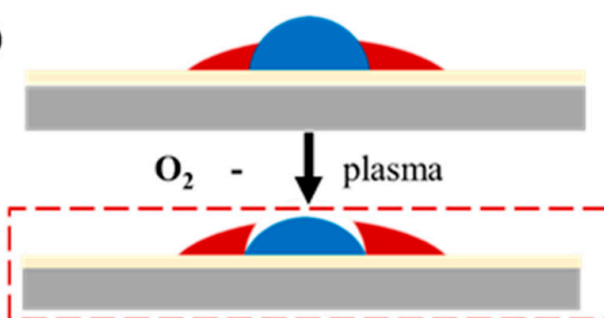

(b)

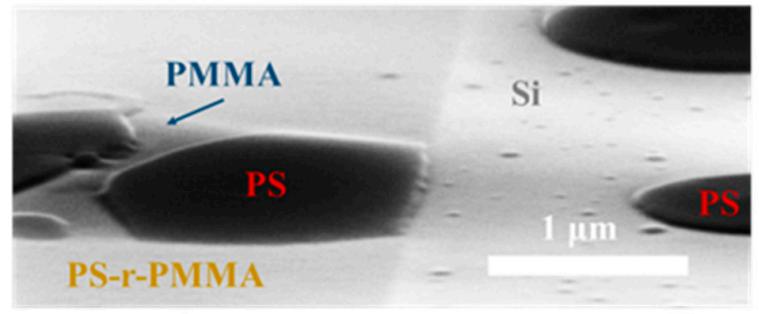

(d)

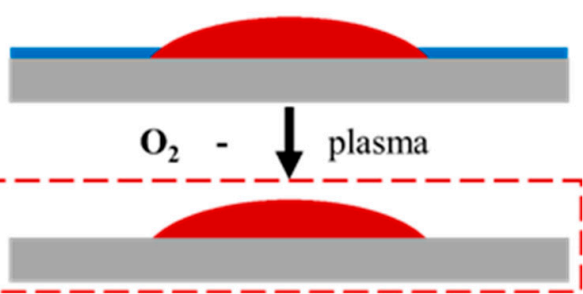


Figure 5. Qualitative analysis of $P S / P M M A$ blends on neutral surfaces and on surfaces modified by m-AFM. (a) Overview SEM image of PS/PMMA blend in two modified areas (stripes) and their direct pristine vicinity covered with neutral brush layer, (b) close-up of the part of (a) indicated by the box drawn in light blue, (c) explanatory sketch of the architecture of the droplet sketched on the left side of (b) before and after the oxygen plasma treatment, (d) explanatory sketch of surface on the right side of image (b).

The phase-separated PS/PMMA droplet in the pristine area of the sample in Figure $5 \mathrm{~b}$ is sketched in Figure $5 c$ and provides valuable insight in the behavior of polymer blends on neutral surfaces. The slightly recessed part of the droplet corresponds to a PMMA droplet inside a PS droplet due to the $\mathrm{O}_{2}$ plasma treatment. This indicates that both polymers have very similar interface energies with respect to the neutral brush layer. The surface energy of PMMA (with respect to the air) is slightly higher than of PS [43], which justifies that the PMMA droplet is inside the PS droplet and not vice versa. A similar behavior has been presented before for the investigation of chemical guiding patterns [42,44].

In contrast, we do not observe these characteristic twin-droplets in the modified areas. This behavior is explained by a homogenous coverage of the silicon by PMMA, because the interface energy between the activated silicon and PMMA is significantly lower than between silicon and PS. The PS thus minimizes its surface energy through the formation of droplets surrounded by a continuous $P M M A$ layer. This concept is sketched in Figure 5d. It is concluded that the surface energy is efficiently modified when the neutral brush layer is removed by m-AFM.

\subsection{Limits of Grain-Boundary-Induced Alignment}

An important feature of the ordering of block copolymers via grain-boundary-induced alignment is that it does not require the fabrication of a high-resolution guiding pattern. This comes, however, at the expense of the fact that the maximum alignment length is limited by the correlation length, $\xi$, of the block copolymer. To estimate a reasonable maximum distance $d$ between the two horizontally aligned grains, we have to know the grain size distribution of the block copolymer finger print after self-assembly.

In Figure 6 we present an estimation of the block copolymer correlation length based on the grazing incidence small angle X-ray scattering (GISAXS) pattern depicted in Figure 6a, similar to how it has already been discussed elsewhere (for example in [44,45]). Moreover, we present an analysis of the width of the first order grating truncation rod (GTR) in Figure 6b, and an SEM image indicating the estimated mean grain size in Figure 6c.

It is well-known that block copolymer self-assembly is a process based on grain nucleation and subsequent growth, also referred to as coarsening [46]. Characterization techniques like small-angle X-ray scattering (SAXS), depolarized light scattering (DPLS) [47], and grazing-incidence small-angle X-ray scattering (GISAXS) [44] are capable of providing mean values [48] for the grain sizes in block copolymers (e.g., correlation length). Nevertheless, the mean value does not, a priori, contain information about the distribution of the grain sizes. However, the experimental analysis of the grain size in the self-assembly of horizontally aligned diblock copolymers by AFM has been demonstrated to be in excellent agreement with a log-normal distribution function [49]:

$$
f(\ln (\xi))=\frac{1}{\sqrt{2 \pi} * \ln (\sigma)} * \exp \left\{-\frac{(\ln (\xi)-\ln (\mu))^{2}}{2 * \ln ^{2}(\sigma)}\right\}
$$

with $\sigma$ being the geometric standard deviation and $\mu$ being the number-based geometric mean, equivalent to the mode diameter of the grain. 
(a)

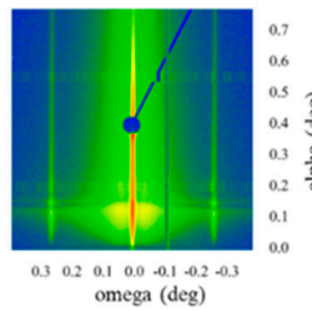

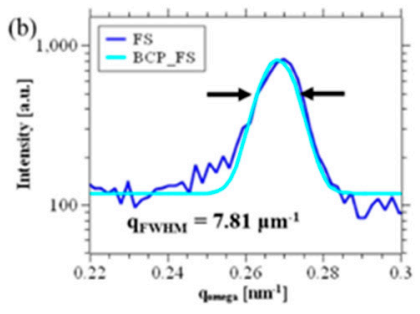

(c)

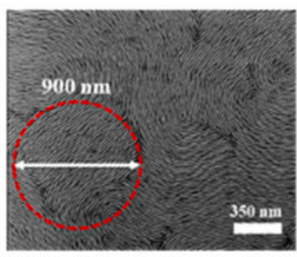

Figure 6. Estimating the limits of the directed self-assembly by grain-boundary-induced alignment. (a) Grazing-incidence small-angle X-ray scattering (GISAXS) pattern of randomly assembled block copolymer features; (b) estimation of the full-width at half maximum (FWHM) of the block copolymer grating truncation rod (GTR) to estimate the mean correlation length $\xi$ of the sample; (c) SEM image of finger-print pattern with a circle representing the mean grain size as determined by the analysis of the GISAXS pattern.

The authors of [49] suggest that the block copolymer grain size can be described by a Smoluchowski coagulation function, for which $\sigma=1.45$; usually used for systems where particle trajectories are controlled by Brownian motion. If the correlation length, $\xi_{\text {GISAXS }}$ as determined by the GISAXS line width analysis, corresponds to the mean correlation length of all grains (in this case $\xi=900 \mathrm{~nm}$ ), we can estimate that the grain size distribution $f(\ln (\xi))$ of our sample is:

$$
f(\ln (\xi))=\frac{1}{\sqrt{2 \pi} * \ln (1.45)} * \exp \left\{-\frac{(\ln (\xi)-\ln (731.7))^{2}}{2 * \ln ^{2}(1.45)}\right\}
$$

(plotted in Figure 7a). The number 731.7 is selected to obtain the experimentally observed value for $\xi_{\text {mean }}$ :

$$
\xi_{\text {mean }}=\frac{\int_{0}^{\infty} \xi * f(\ln (\xi)) d \xi}{\int_{0}^{\infty} f(\ln (\xi)) d \xi}=900 \mathrm{~nm}
$$

Knowing the approximate grain size distribution of our block copolymer in free surface $f(\ln (\xi))$, we can estimate the probability $p[\%]$, that a grain of the sample is smaller than a determined value $\xi_{0}$ :

$$
p\left(\xi_{0}\right)=100 * \frac{\int_{0}^{\xi_{0}} f(\ln (\xi)) d \xi}{\int_{0}^{\infty} f(\ln (\xi)) d \xi}[\%]
$$

The particle distribution function in Figure 7a is divided in a red and a blue area. The surface area of the red part divided by the total area represents the probability $p\left(\xi_{0}\right)$ that an areal unit forms part of a grain smaller than $\xi_{0}=450 \mathrm{~nm}$, which in this case is $4.8 \%$. Accordingly, $0.3 \%$ of the total area is occupied by grains with the size of $300 \mathrm{~nm}$ and merely $7 \times 10^{-10 \%}$ of the area is occupied by grains smaller than $65 \mathrm{~nm}$.

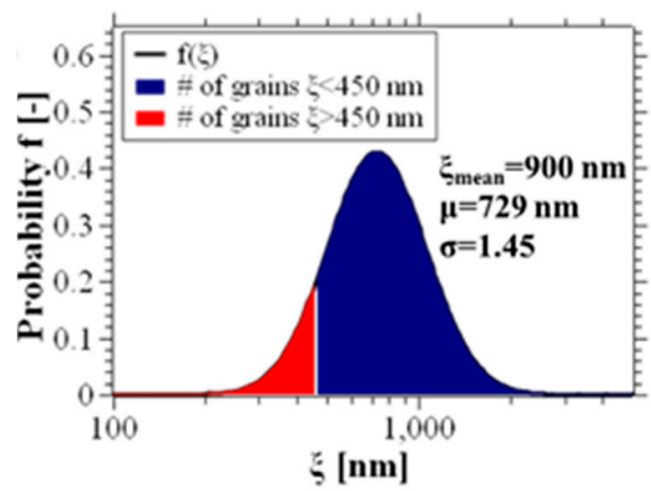

Figure 7. Grain size analysis in block copolymer thin films. Grain size distribution for the block copolymer in free surface for $\xi_{\text {mean }}=900 \mathrm{~nm}$ 
The self-assembly in structures like the ones we fabricate in this work is considered to be successful if there is no defect on the entire length of the grain. We can estimate the probability $p_{\bar{d}}$ of this event by estimating the probability that all the grains along the grain boundary with the length $l$ are at least as large as the distance $d$ between the two grain boundaries, which is given by the term:

$$
p_{\bar{d}}=p\left(\xi_{0}=d\right)^{\frac{l}{d}}
$$

In the table presented in Table 1 we present the probability to fabricate a $l=5 \mu \mathrm{m}$ long array without defects for three different lengths of $d$. The values for $d$ we worked with in this table are process parameters used in this section. In particular, we have presented the grain boundary-induced alignment with $d=300 \mathrm{~nm}$ in Figure 2 fabricated by m-AFM and $d=65 \mathrm{~nm}$ in Figure 3 by e-beam direct writing and we observe no defects in these structures-just as predicted by the presented estimation. The fact that a $p_{\bar{d}}(d=450 \mathrm{~nm})$ yields less than $60 \%$ indicates that the probability to find defects in such a structure rather high. An example of a structure with $d=450 \mathrm{~nm}$ is depicted in Figure 8 a and we observe the formation of defects.

Table 1. Results for the probability of defect free self-assembly between two $5 \mu \mathrm{m}$ grain boundaries for three characteristic distances d between the grains. Average correlation length $\xi_{\text {mean }}$ is $900 \mathrm{~nm}$.

\begin{tabular}{cc}
\hline Distance $\boldsymbol{d}$ between Two Grains & Probability $\boldsymbol{p}_{\boldsymbol{d}}$ of Defect-Free Self-Assembly \\
\hline $65 \mathrm{~nm}$ & $99.99999 \%$ \\
$300 \mathrm{~nm}$ & $95.15 \%$ \\
$450 \mathrm{~nm}$ & $57.89 \%$ \\
\hline
\end{tabular}

(a)

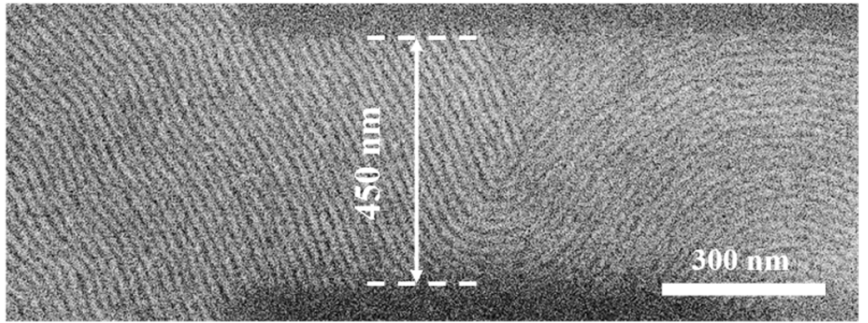

(b)

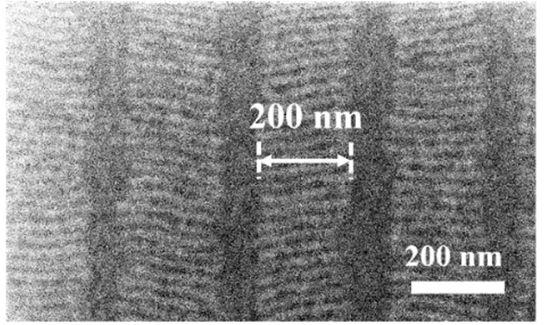

(c)

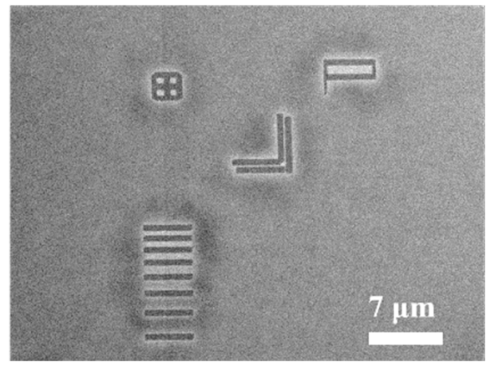

(d)

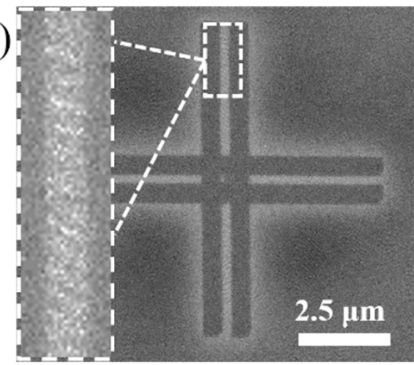

(e)

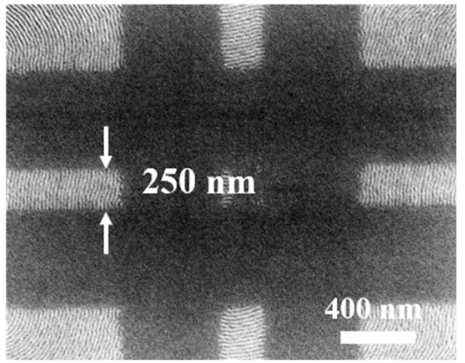

Figure 8. Alternative structures fabricated by grain-boundary-induced alignment. (a) Defective self-assembly due to a too large distance between the two grain boundaries; (b) self-assembly of multiple arrays of parallel lamella; (c) arbitrary shapes fabricated by mechanical AFM removal; (d,e) double-bar cross defined by mechanical AFM removal.

Based on the presented analysis, the self-assembly of block copolymers by grain-boundary-induced alignment mainly depends on the correlation length $\xi$ of the block copolymer (material parameter), and on the distance $d$ between the two horizontally aligned grains and the length $l$ of the horizontally aligned grains (process parameters). For this reason, it is important to understand the mechanisms of self-assembly and defect-annihilation in detail, which has already been subject to a number of works $[41,44,50,51]$. 
The rate at which a block copolymer eliminates defects in the course of the self-assembly process is determined by the energy barrier that has to be overcome in order to annihilate the defect [52]. Here, a smaller energy barrier indicates a faster defect removal mechanism which is expressed by a higher degree of order in the block copolymer. In [52] the authors demonstrate that the energy barrier for the defect removal is inversely proportional to $\chi \mathrm{N}$. A direct consequence of that is that the correlation length $\xi$ of block copolymers is larger for small-pitch materials (e.g., materials with small $\chi \mathrm{N})$. This means that an inherent property of grain-boundary-induced alignment is the decreasing number of defects for smaller-pitch materials. Additionally, the influence of different fractions of homopolymer in the block copolymer on both grain boundary energy and correlation length is investigated and presented in Appendix A.3.

\subsection{Fabrication of Patterns of Arbitrary Geometry}

The fabrication of patterns to direct the self-assembly of block copolymers by grain-boundary-induced alignment by m-AFM is not limited to trapping one single grain, which has been the only structure that we have discussed until now. In Figure $8 \mathrm{~b}-\mathrm{e}$, we present alternative structures fabricated by grain-boundary-induced alignment, such as defect-free array of nanowires of $200 \mathrm{~nm}$ in length and a pitch of $250 \mathrm{~nm}$ in Figure 8b. In Figure 8c we show a number of geometric shapes that have been fabricated to demonstrate the versatility of the technique. A double-lined cross of $10 \mu \mathrm{m} \times 10 \mu \mathrm{m}$ with a line width of $500 \mathrm{~nm}$ and $250 \mathrm{~nm}$ spaces between the lines is depicted in Figure $8 \mathrm{~d}$,e. The in-set of Figure $8 \mathrm{~d}$ shows the Moiré pattern between the two branches of the cross, which indicates the high order of the block copolymer without actually having sufficient measurement points to resolve single block copolymer domains. Moiré patterns are interference patterns [53] that occur when a periodic lattice (for example a directed block copolymer pattern) is measured with an imaging technique whose sampling step size is below the step size of the lattice that is supposed to be measured. The existence of the Moiré pattern hence can be understood as a proof for the successfully directed self-assembly of the block copolymers between the two branches of the cross. To verify this thesis, we show a close-up of the center of the fabricated cross in Figure 8e, where we doubtlessly see the directed self-assembly of block copolymers is successful in each one of the four trapped grains.

\section{Materials and Methods}

\subsection{Substrate}

The substrate are chips cut from a $<100>\mathrm{Si}$ wafer. Native oxide is not removed. After cleaning the substrate in isopropyl alcohol and acetone, the substrate undergoes an oxygen plasma treatment for $600 \mathrm{~s}$ at $500 \mathrm{~W}$.

\subsection{Neutral Brush Layer Deposition}

The neutral brush layer consists of grafted PS-r-PMMA polymer chains (58 wt\% $P S, 42 \mathrm{wt} \%$ $P M M A, \mathrm{M}_{\mathrm{p}}=7.9 \mathrm{~kg} / \mathrm{mol}$ and polydispersity index 1.85) yielding a film thickness of 6.5 . To deposit the neutral brush layer, $1.5 \mathrm{wt} \%$ of $P S-r-P M M A$ is dissolved in PGMEA and the solution is spin-coated to the silicon wafer for $30 \mathrm{~s}$ at $5000 \mathrm{rpm}$. To graft the molecules to the surface, the chip is annealed at $230{ }^{\circ} \mathrm{C}$ in a nitrogen atmosphere for $300 \mathrm{~s}$. The non-grafted molecules are removed by rinsing the sample in PGMEA. All the polymer materials have been supplied by Arkema (Colombes, France).

\subsection{Guiding Pattern Fabrication}

In this work we use two different methods to fabricate the guiding patterns. The guiding pattern fabrication by AFM consists of removing the neutral brush layer in two elongated rectangular areas of $500 \mathrm{~nm} \times 5 \mu \mathrm{m}$ separated by a distance $d$ in the range of few hundreds of nanometers. The brush removal is done by mechanical AFM using the contact mode of a Dimension Icon/Nanoscope V AFM (Bruker Corporation, Billerica, MA, USA). The tips used in these experiments (OTESPA, also from 
Bruler, Si-tip with nominal spring constant $42 \mathrm{~N} / \mathrm{m}$ ) have a nominal apex radius of $7 \mathrm{~nm}$ in the unused state. We estimate the contact force for the probed deflection set-points to be between $0.26 \mu \mathrm{N}$ and $2.34 \mu \mathrm{N}$. The AFM height image shown in Figure 1b shows the efficiency of the polymeric brush layer removal as a function of the contact force. The contact force has been increased by $0.26 \mu \mathrm{N}$ for each segment of the spiral going from the inside to the outside. The fabrication of the structures presented in this article has been conducted with nominal contact force of $1.04 \mu \mathrm{N}$, because this condition represents the minimum required force to remove the polymer film down to the substrate.

The second approach to fabricate the guiding patterns is based on the modification of the brush layer by direct e-beam exposure. The exposure has been performed in a RAITH 150 (TWO) electron lithography tool (Raith Gmbh, Dortmund, Germany) with a nominal beam diameter of $2 \mathrm{~nm}$. We expose lines of $50 \mu \mathrm{m}$ in length and between $65 \mathrm{~nm}$ and $500 \mathrm{~nm}$ in width, with separations between $500 \mathrm{~nm}$ and $65 \mathrm{~nm}$. We applied the same conditions as used in reference [26]: electron beam with $20 \mathrm{kV}$ acceleration voltage; sample current of $330 \mathrm{pA}$; exposure dose of $256 \mathrm{mC} / \mathrm{cm}^{2}$.

\subsection{Block Copolymer Deposition}

The diblock copolymer is a PS- $b-P M M A$ (Arkema (Colombes, France) consisting of $42 \mathrm{wt} \%$ PS and $58 \mathrm{wt} \%$ PMMA. Upon self-assembly, this material forms $23.4 \mathrm{~nm}$ full-pitch lamellar features. Its polydispersity index $P D I$ is 1.1 , and the molecular weight is $42.3 \mathrm{~kg} / \mathrm{mol}$. A $1.7 \mathrm{wt} \%$ solution of the polymer in PGMEA is deposited by spin coating for $30 \mathrm{~s}$ at $2500 \mathrm{rpm}$ and subsequently annealed for $600 \mathrm{~s}$ in a $N_{2}$ atmosphere at $230{ }^{\circ} \mathrm{C}$. This process yields a film thickness of $24 \mathrm{~nm}$ in free surface.

\subsection{Pattern Transfer}

The pattern transfer consists of two steps. At first, the PMMA block is removed in a selective dry etching step in an Alcatel AMS 110 DE ICP-RIE. (Inductively coupled plasma reactive ion etching). We used etching conditions similar to those previously successfully developed and used by the authors of reference [54]: a gas mixture of $200 \mathrm{sccm} A r$ and $10 \mathrm{sccm} \mathrm{O}_{2}$ with at $200 \mathrm{~W}$ source power and $5 \mathrm{~W}$ substrate power. The etch selectivity of PS with respect to PMMA in this process is 1:3 with PS being the more resistant material. The etching time for this step is $21 \mathrm{~s}$. For the subsequent $S i$ etching we use the same RIE tool with a plasma power of $1200 \mathrm{~W}$ and a substrate power of $10 \mathrm{~W}$ for $12 \mathrm{~s}$. The used gases are $30 \mathrm{sccm} S F_{6}$ and $25 \mathrm{sccm} C_{4} F_{8}$. We employ an etch process in which both gases are injected in the reaction chamber in a non-pulsed way.

\subsection{GISAXS Measurements}

GISAXS measurements of a representative sample have been conducted at the P03 Micro- and Nanofocus X-Ray Scattering Beamline at PETRA III in Hamburg [55]. The sample-detector distance was $5800 \mathrm{~mm}$ and the radiation wavelength $0.107 \mathrm{~nm}$. The incidence angle of the beam was $0.4^{\circ}$. The detector that has been used for these experiments is a PILATUS 300k pixel detector (ECTRIS Ltd., Baden-Daettwil, Switzerland) with a readout time $t<3 \mathrm{~ms}$ and a pixel size of $172 \mu \mathrm{m}$.

\section{Conclusions}

We have shown that the directed self-assembly of block copolymers by grain boundary induced alignment is possible either by the controlled removal of an intermediate polymeric brush layer or its local surface modification. We have shown this concept using both a probe-based mechanical removal approach and an electron-beam direct writing approach.

The driving force of the self-assembly is the energy minimization process in the grain boundary between horizontally and vertically assembled block copolymers. This specific grain boundary is referred to as $90^{\circ}$ twist grain boundary, where the PS/PMMA surface is reduced to a first Scherk surface, which mathematically represents a minimal surface. Because this approach does not require a guiding pattern along the self-assembly direction, the correlation length $\xi$ is the limiting factor for the defect-free alignment. 
For this reason, grain-boundary-induced alignment represents a particularly interesting alternative for early stage testing of new high- $\chi$, low-pitch block copolymers with large correlation lengths. A recent report on the self-assembly of sub-5 nm liquid crystals (with a remarkably high degree of intrinsic order) has shown that the alignment of very small features by the mean of graphoepitaxy may be perturbed by large guiding pattern roughness [20]. Grain-boundary-induced alignment offers one possible solution for upcoming challenges that may be encountered by graphoepitaxy (and also chemoepitaxy), which is the difficulty to provide reliable guiding patterns for very small pitch self-assembling materials. Grain-boundary-induced alignment, in turn, favors the directed self-assembly of materials with small pitches due to their large correlation length.

On the down-side, we have to remark that the limited placement accuracy of the block copolymer features may represent an issue that requires improvement. This study presents a straight forward way to direct the self-assembly of block copolymers by taking advantage of the grain boundaries created between two differently oriented areas of block copolymers.

Author Contributions: Conceptualization, S.G. and F.P.-M.; validation, S.G., M.L., L.E., M.F.-R., and F.P.-M.; formal analysis, S.G. and F.P.-M.; investigation, S.G.; resources, F.P.-M.; draft preparation, S.G. and F.P.-M.; visualization, S.G., M.L., and F.P.-M.; supervision, F.P.-M.; project administration, F.P.-M.; funding acquisition, F.P.-M. All authors have read and agreed to the published version of the manuscript.

Funding: This research was funded by the EU project NFFA, grant number 654360 and by the Spanish project NANOINTEGRA (TEC2015-69865-R) and STARSED (RTI2018-102007-B-I00).

Acknowledgments: The authors would like to acknowledge Christophe Navarro and Celia Nicolet from Arkema for supplying some of the polymers used in this work. We would, furthermore, like to acknowledge the team of the P03 Micro- and Nanofocus X-Ray Scattering Beamline at PETRA III in Hamburg, Germany and in particular Björn Beyersdorff for his technical support during the GISAXS measurements.

Conflicts of Interest: The authors declare no conflict of interest.

\section{Appendix A.}

\section{Appendix A.1. Overview of Grain Boundary Morphologies in Block Copolymers}

Two relevant types of grain boundaries are the twist grain boundary at one hand (see Figure A1) and the tilt grain boundary on the other hand (see Figure A2). As for lamellar block copolymers, the grain boundary free energy is a function of the area of the intermaterial dividing surface (IMDS) and the stretching and the compression of molecules in the close vicinity of the grain boundary. The material usually tries to reduce the area of the IMDS by stretching and compressing adjacent chains.
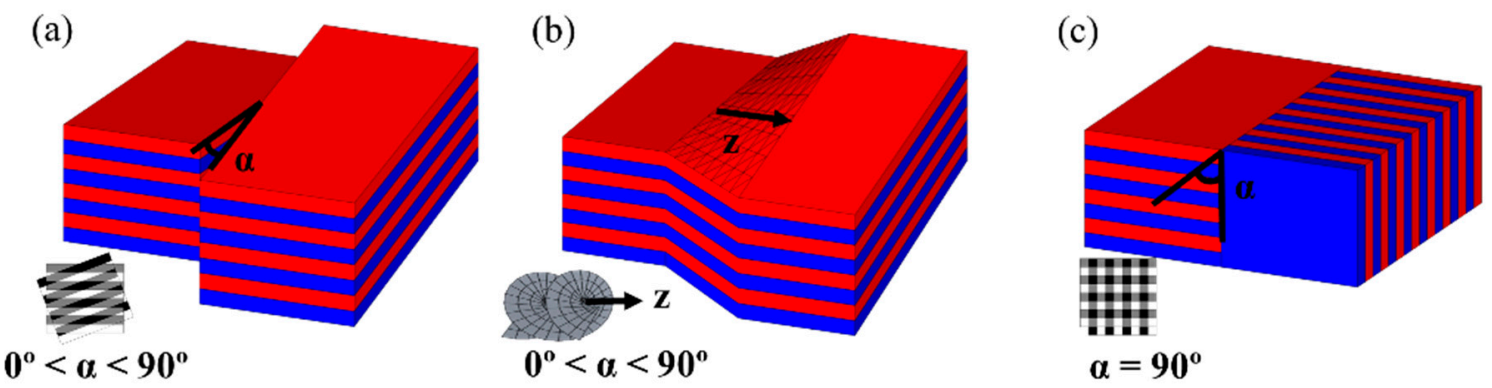

Figure A1. Different types of twist grain boundaries and their corresponding inter-material dividing surface (IMDS). (a) Two grains of lamellar block copolymers under a twist angle $\alpha \ll 90^{\circ}$; the grey areas of the inset represent the IMDS reconstructed in a Scherk surface; (b) two grains of lamellar block copolymers under a twist angle $\alpha \ll 90^{\circ}$, the inset represent the IMDS reconstructed in a helicoid shape; (c) two grains of lamellar block copolymers under a twist angle of $90^{\circ}$, the grey areas of the inset represent the IMDS reconstructed in a Scherk surface. 

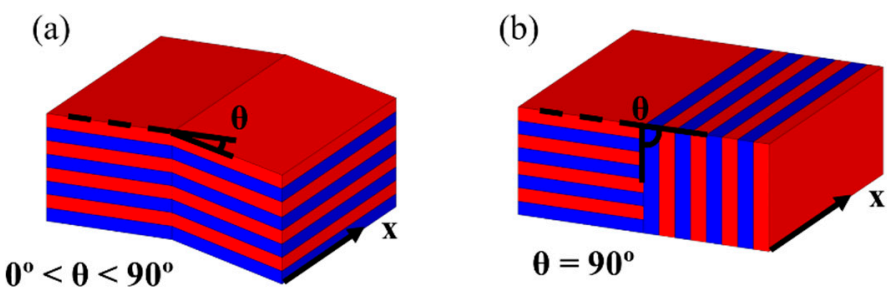

(c)

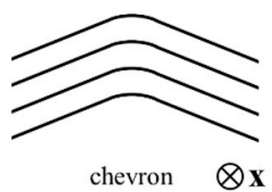

(d)

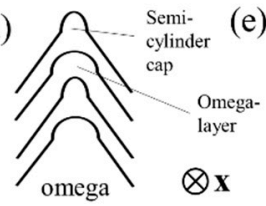

(e) layer

$\otimes x$

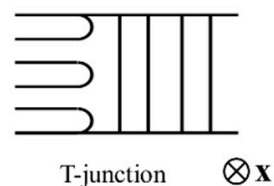

T-junction $\otimes \mathbf{x}$

Figure A2. Overview of tilt grain boundary morphologies. (a) Two grains of lamellar block copolymer tilted under an angle well below $90^{\circ},(\mathbf{b})$ :two grains of lamellar block copolymer tilted under an angle of $90^{\circ}$, (c) 2D-scheme of the IMDS of a low-tilt-angle chevron grain boundary, (d) 2D-scheme of the IMDS of an omega grain boundary, (e) 2D-scheme of the IMDS of a pure T-junction as observed in $90^{\circ}$ tilt grain boundaries.

For twist angles $\alpha<15^{\circ}$ we observe two different reconstruction moduli, which are called helicoid interphase and Scherk first surface [32,34]. The two morphologies coexist for low angles because of their similar grain boundary energies (see Figure A1a,b). The major difference between these two morphologies is the shape of the IMDS. There is no major reconstruction mechanism in the formation of helicoid grain boundaries (see shape of the respective IMDS in inset of Figure A1b)). In the second case, the first Scherk surface, the IMDS is reconstructed to a distorted chess board pattern, as described in [31]. The IMDS in these structures can be mathematically described as a first Scherk surface, which forms part of the family of minimal surfaces [56]. The insets of Figure A1a,c represent a scheme of the situation inside the grain boundary. Here, white and black areas represent A-A-block interfaces and B-B-block interfaces, respectively. The actual IMDS is represented by the grey areas, which represent A-B-block interfaces. The reconstruction of twist grain boundaries in first Scherk surfaces has been observed experimentally $[27,29]$. For better understanding, we have plotted a scheme of a first Scherk surface as it occurs in $90^{\circ}$ twist grain boundaries in Figure A1d. For large twist angles $\left(\alpha \gg 15^{\circ}\right)$, the formation of first Scherk surfaces is energetically favorable when compared to helicoid grain boundaries. This is at one hand because the helicoid grain boundary massively compresses the lamellae (and therefore the chains) at large angles. On the other hand, the first Scherk surface is by definition a minimal surface that minimizes the IMDS at large twist angles of $\alpha=90^{\circ}$.

Tilt grain boundaries represent another grain boundary family commonly observed in bulk block copolymer samples. Schemes of two grains under a low tilt angle $\theta \ll 90^{\circ}$ and under a tilt angle $\theta$ $=90^{\circ}$ are represented in Figure A2a,b. Low angle tilt grain boundaries are sub-divided in so-called chevron tilt grain boundaries and omega tilt grain boundaries. While the chevron tilt grain boundary is rather prominent at low tilt angles, the omega grain boundary tends to be the result of energy minimization at larger tilt angles [33]. As we can tell from the two sketches depicted in Figure A2c,d, both morphologies are similar in appearance. The sequence of the omega-layers and semicylinder caps [33] in omega tilt grain boundaries efficiently minimizes the grain boundary energy at higher angles. When the tilt angle increases even more and $\theta$ approaches $90^{\circ}$ (see Figure A2b), the most efficient manner to minimize the free energy of the system is to interrupt the continuity of one of the species and reorganize them in semicylinder caps as shown in Figure A2e.

$90^{\circ}$ tilt and $90^{\circ}$ twist grain boundary structures, as sketched in Figures A1c and A2b, may form in block copolymer thin films, when a vertically oriented grain is adjacent to a horizontally oriented grain. This situation may occur wherever the surface energy changes abruptly from a neutral surface to a highly preferentially wetted surface. Taking into consideration that the block copolymer features 
on neutral surfaces are upright standing lamellae, the only two structures that may be formed in such grain boundaries are the $90^{\circ}$ tilt grain boundary and the $90^{\circ}$ twist grain boundary. In reference [36] the authors argue that the free energy of $90^{\circ}$ twist grain boundaries is around half of the free energy of $90^{\circ}$ tilt grain boundaries, which heavily benefits the formation of twist grain boundaries. This calculation is moreover supported by the fact that $90^{\circ}$ twist grain boundaries, and the resulting tendency to form Scherk's first surface IMDSs, are also observed in the terraced self-assembly horizontally aligned block copolymers on preferentially wetting substrates [57].

\section{Appendix A.2. Fixed-Height Self-Assembly}

Transferring the created block copolymer patterns into the underlying substrate is a key step that converts block copolymer lithography into a purposeful technique for semiconductor manufacturing. Here, the pattern transfer process is particularly challenging, because polystyrene and poly(methyl methacrylate) are chemically similar. Despite of PS being chemically relatively inert, it does by far not show etch resistances as large as an inorganic hard mask would do. This leads to fast mask wear and requires exact knowledge about the film thickness of the initial block copolymer film to design a successful pattern transfer process. Nanometric fluctuations of the block copolymer thickness throughout the wafer/chip area due to microscopic impurities or other process-related issues may lead to difficulties in the pattern transfer process.

The self-assembly of block copolymers between two grain boundaries is quantized to multiples of $0.5 \mathrm{~L}_{0}$, because of the adjacent horizontally oriented grains' quantized height. This concept is clarified in Figure A3, where we present a measurement of the block copolymer height in the horizontally aligned (and previously modified) area. The block copolymer has been removed by m-AFM in an area orthogonal to the long axis of the modified area, and an AFM height image of one part of the sample is depicted in Figure A3a. A single line AFM height profile is shown in Figure A3b. The profile's precise location and direction is indicated by the white dashed line both in the sketch and in the actual height image. The step height is $35 \mathrm{~nm}$, which corresponds to $1.5 \mathrm{~L}_{0}$ (with $\mathrm{L}_{0}$ being $23.4 \mathrm{~nm}$ ). Based on the knowledge that the silicon wafer is preferentially wetted by $P M M A$, we conclude that the top layer must be $P S$, as sketched in Figure A3c.

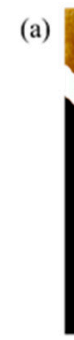

(d)

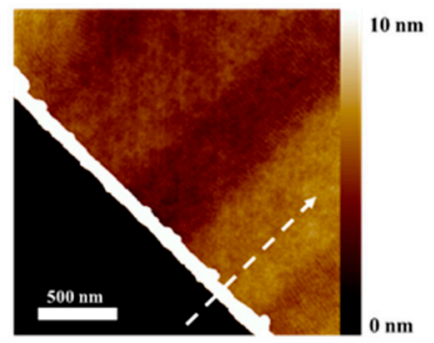

d) $\quad 0.5 \mathbf{L}_{0}$

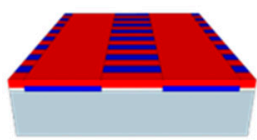

$\mathbf{L}_{0}$

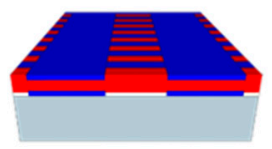

(b)

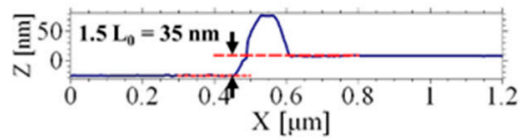

(c)

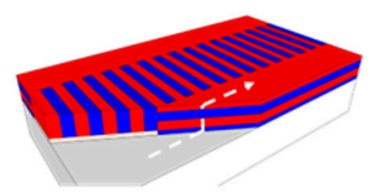

$1.5 \mathrm{~L}_{0}$

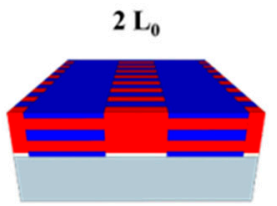

Figure A3. Measuring the height step between substrate and horizontally aligned block copolymer lamellae. (a) AFM height image of prepared sample; (b) single line profile indicated by white dashed line in (a); (c) 3D sketch of the measurement presented in (a); (d) possible self-assembly morphologies with height quantized to from $0.5 \mathrm{~L}_{0}-2 \mathrm{~L}_{0}$ in steps of $0.5 \mathrm{~L}_{0}$.

Figure A3d presents a sketch of four different self-assembly heights in steps of $0.5 \mathrm{~L}_{0}$. We would like to state at this point that the horizontally aligned areas will self-assemble in a quantized state such that the film height in the horizontally aligned area is always an integer multiple of $0.5 \mathrm{~L}_{0}$. Interestingly, we observe in all our experiments that the self-assembly of block copolymers in the vertically aligned 
trapped grain is few nanometers recessed with respect to the horizontally aligned grains. The opposite has been observed by other authors in a similar experiment [58], where the vertically assembled block copolymer domain is few nanometers higher than the horizontally aligned domain. In both cases the deviation of the vertical lamellae height from the quantized horizontal lamellae height is few nanometers.

\section{Appendix A.3. Grain-Boundary-Induced Alignment with Ternary Blends}

For the application of grain-boundary-induced alignment it could be favorable to achieve an alignment mode that is not restricted by the correlation length of the block copolymer. One way to do so is to influence the material is such a way that the preferentially formed grain boundary is a $90^{\circ}$ tilt grain boundary (see Figure A1c) instead of a $90^{\circ}$ twist grain boundary (see Figure A2b). This is the case when the vertical interface created by the horizontally ordered block copolymer is energetically more attractive to one block than for the other, similar to the energetic situation in graphoepitaxy.

Duque et al. [39] calculated the free energy in twist and tilt grain boundaries for a pure diblock copolymer and a ternary blend containing 70\% diblock copolymer and a 30\% fraction of homopolymers. The calculation yields that $90^{\circ}$ tilt grain boundaries have the same (or in the concrete case of mixing in $30 \%$ homopolymers an almost negligible $2 \%$ lower) grain boundary free energy compared to the $90^{\circ}$ twist grain boundary in case of mixing in homopolymers. The $90^{\circ}$ twist grain boundary has, in turn, a clear energetic advantage over the $90^{\circ}$ tilt grain boundary in case of pure diblock copolymers. Moreover, the absolute grain boundary free energy for the ternary blend is reduced heavily to approximately $1 / 3$ of the value for the pure block copolymer.

We reproduced this experiment using a blend of the $23.4 \mathrm{~nm}$ pitch $P S-b-P M M A$ and different amounts of PS and PMMA with a molecular weight of $39.5 \mathrm{~kg} / \mathrm{mol}$ with a total accumulated homopolymer fractions between $0 \%$ and $45 \%$. In all the experiments, the volume fraction of $P S$ and PMMA is equal. Results of the behavior of the ternary block copolymer/homopolymer blend in the vicinity of a grain boundary is presented in Figure A4. The annotation in the respective SEM images in Figure A4 refers to the accumulated homopolymer fraction, which means that " $30 \% \mathrm{HP}$ " in Figure A4b indicates that the ternary blend contains 15\% PS, 15\% PMMA, and 70\% PS- $b-P M M A$.

We observe two different effects caused by the increasing homopolymer fraction. At one hand, we observe a progressive swelling of the block copolymer features due to the accumulation of homopolymer molecules in the center of the domain (because this is the place where the molecules can avoid the energetically unfavorable location close to the IMDS). This effect is accompanied by a decrease of the material's correlation length.

(a)

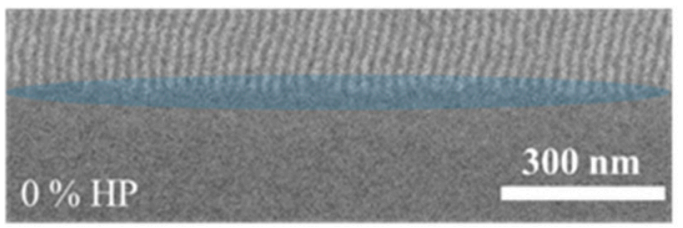

(b)

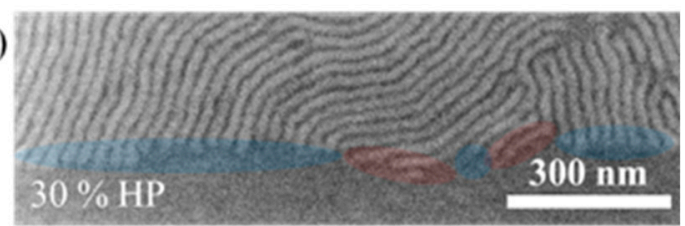

(c)

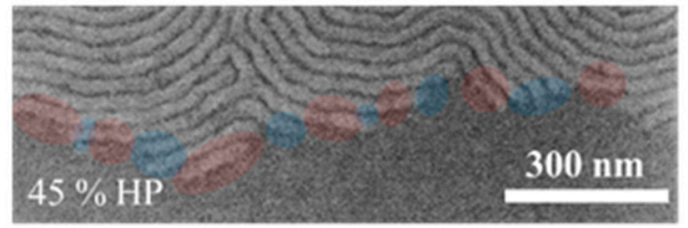

Figure A4. Grain boundary evolution as function of homopolymer content in the ternary blend. (a) $0 \%$ homopolymer, (b) 30\%, (c) 45\%; tilt grain boundaries and the blue areas are marked in red and twist grain boundaries are marked in blue. 
On the other hand, we observe that the proportion of tilt grain boundaries rises upon increasing the homopolymer ratio. Those parts of the grain boundary that correspond to a tilt grain boundary are red shaded, while twist grain boundaries are marked blue (see Figure A4). As a general trend we can state, that the block copolymer is more likely to form tilt grain boundaries at increasing homopolymer fractions. This behavior is explained by the reduction of the free energy difference between the two grain boundary morphologies. The formation of tilt grain boundaries does, however, not convert into the energetically clearly favorable state. The proportion of tilt grain boundaries and twist grain boundaries for the $45 \%$ homopolymer sample is approximately equal, as shown in Figure A4c. This observation indicates that the energetic difference between the two states is very low.

The desired situation we describe in the introductory paragraph is, however, only achieved if the formation of a tilt grain boundary is energetically favorable for one particular block, but not for the other one. This effect may be better understood when we consider ref. [59], where the authors observe that added $P S$-coated $A u$ nanoparticles accumulate particularly in grain boundaries. There, the nanoparticles minimize the $\mathrm{A} / \mathrm{B}$ interface area of the-in that case-PS-b-PEO block copolymer in favor of the PS-block. The alignment of block copolymers via grain-boundary-induced alignment parallel to the grain boundary can be successful, in case two prerequisites are fulfilled: (i) the total homopolymer fraction in the blend is large enough to lower the tilt grain boundary free energy significantly and (ii) the ratio of the two homopolymers in the blend is sufficiently asymmetric that the tilt grain boundary is reduced significantly more for one block than for the other.

In reference [60] the authors make use of asymmetric ternary blends with a total of $40 \%$ homopolymers (e.g., 29\% PMMA and 11\% PS) to provoke the formation of tilt grain boundaries. The alignment of the block copolymers in that work, is however accompanied by the use of high-resolution chemical guiding patterns, which we believe would not be necessary for sufficiently high-correlation-length blends. The effect of having worked with a ternary blend could represent an explanation for the unusual self-assembly morphology that is observed, but not further explained, in reference [58].

\section{References}

1. Bates, F.S.; Fredrickson, G.H. Block Copolymers-Designer Soft Materials. Phys. Today 1999, 52, 32-38. [CrossRef]

2. Yang, X.; Xiao, S.; Hu, W.; Hwu, J.; Van De Veerdonk, R.; Wago, K.; Lee, K.; Kuo, D. Integration of nanoimprint lithography with block copolymer directed self-assembly for fabrication of a sub-20 nm template for bit-patterned media. Nanotechnology 2014, 25, 1-11. [CrossRef] [PubMed]

3. Ruiz, R.; Dobisz, E.; Albrecht, T.R. Rectangular Patterns Using Block Copolymer Directed Assembly for High Bit Aspect Ratio Patterned Media. ACS Nano 2011, 5, 79-84. [CrossRef] [PubMed]

4. Griffiths, R.A.; Williams, A.; Oakland, C.; Roberts, J.; Vijayaraghavan, A.; Thomson, T. Directed self-assembly of block copolymers for use in bit patterned media fabrication. J. Phys. D Appl. Phys. 2013, 46, 1-29. [CrossRef]

5. Tsai, H.; Pitera, J.W.; Miyazoe, H.; Bangsaruntip, S.; Engelmann, S.U.; Liu, C.C.; Cheng, J.Y.; Bucchignano, J.J.; Klaus, D.P.; Joseph, E.A.; et al. Two-dimensional pattern formation using graphoepitaxy of PS-b-PMMA block copolymers for advanced FinFET device and circuit fabrication. ACS Nano 2014, 8, 5227-5232. [CrossRef]

6. Yi, H.; Bao, X.Y.; Tiberio, R.; Wong, H.S.P. A general design strategy for block copolymer directed self-assembly patterning of integrated circuits contact holes using an alphabet approach. Nano Lett. 2015, 15, 805-812. [CrossRef]

7. Li, W.; Müller, M. Defects in the Self-Assembly of Block Copolymers and Their Relevance for Directed Self-Assembly. Annu. Rev. Chem. Biomol. Eng. 2015, 6, 187-216. [CrossRef]

8. Neisser, M.; Wurm, S. ITRS lithography roadmap: 2015 challenges. Adv. Opt. Technol. 2015, 4, 235-240. [CrossRef]

9. Yoshida, A.; Yoshimoto, K.; Ohshima, M. Effect of wall potential on morphology of symmetric diblock copolymers in nanotrench. Jpn. J. Appl. Phys. 2016, 55, 06GE01. [CrossRef]

10. Chen, W.; Luo, J.; Shi, P.; Li, C.; He, X.; Hong, P.; Li, J.; Zhao, C. Self-assembling morphologies of symmetrical PS b-PMMA in different sized confining grooves. RSC Adv. 2014, 4, 50393-50400. [CrossRef] 
11. Han, B.E.; Kang, H.; Liu, C.; Nealey, P.F.; Gopalan, P. Graphoepitaxial Assembly of Symmetric Block Copolymers on Weakly Preferential Substrates. Adv. Mater. 2010, 22, 4325-4329. [CrossRef] [PubMed]

12. Borah, D.; Rassapa, S.; Shaw, M.T.; Hobbs, R.G.; Petkov, N.; Schmidt, M.; Holmes, J.D.; Morris, M. Directed self-assembly of PS-b-PMMA block copolymer using HSQ lines for translational alignment. J. Mater. Chem. C 2013, 1, 1192-1196. [CrossRef]

13. Ilievski, F.; Ross, C.A. Graphoepitaxy of block copolymers using selectively removable templates. J. Vac. Sci. Technol. A 2010, 28, 42-44. [CrossRef]

14. Borah, D.; Cummins, C.; Rasappa, S.; Senthamaraikannan, R.; Salaun, M.; Zelsmann, M.; Liontos, G.; Ntetsikas, K.; Avgeropoulos, A.; Morris, M.A. Nanopatterning via self-assembly of a lamellar-forming polystyrene-block-poly(Dimethylsiloxane) diblock copolymer on topographical substrates fabricated by nanoimprint lithography. Nanomaterials 2018, 8, 32. [CrossRef] [PubMed]

15. Walton, D.; Kellogg, G.J.; Mayes, A.; Lambooy, P.; Russell, T.P. A Free Energy Model for Confined Diblock Copolymers. Macromolecules 1994, 27, 6225-6228. [CrossRef]

16. Turner, M.S. Equilibrium Properties of a Diblock Copolymer Lamellar Phase Confined between Flat Plates. Phys. Rev. Lett. 1992, 69, 1788-1791. [CrossRef] [PubMed]

17. Gottlieb, S.; Kazazis, D.; Mochi, I.; Evangelio, L.; Fernández-Regúlez, M.; Ekinci, Y.; Perez-Murano, F. Nano-confinement of block copolymers in high accuracy topographical guiding patterns: Modelling the emergence of defectivity due to incommensurability. Soft Matter 2018, 14. [CrossRef]

18. Cummins, C.; Bell, A.; Morris, M. Creating Active Device Materials for Nanoelectronics Using Block Copolymer Lithography. Nanomaterials 2017, 7, 304. [CrossRef]

19. Borah, D.; Shaw, M.T.; Holmes, J.D.; Morris, M.A. Sub-10 nm Feature Size PS-b-PDMS Block Copolymer Structures Fabricated by a Microwave-Assisted Solvothermal Process. ACS Appl. Mater. Interfaces 2013, 5, 2004-2012. [CrossRef]

20. Nickmans, K.; Murphy, J.N.; De Waal, B.; Leclère, P.; Doise, J.; Gronheid, R.; Broer, D.J.; Schenning, A.P.H.J. Sub-5 nm Patterning by Directed Self-Assembly of Oligo (Dimethylsiloxane) Liquid Crystal Thin Films. Adv. Mater. 2016, 28, 10068-10072. [CrossRef]

21. Kim, S.O.; Solak, H.H.; Stoykovich, M.P.; Ferrier, N.J.; De Pablo, J.J.; Nealey, P.F. Epitaxial self-assembly of block copolymers on lithographically defined nanopatterned substrates. Nature 2003, 424, 411-414. [CrossRef] [PubMed]

22. Liu, C.C.; Han, E.; Onses, M.S.; Thode, C.J.; Ji, S.; Gopalan, P.; Nealey, P.F. Fabrication of lithographically defined chemically patterned polymer brushes and mats. Macromolecules 2011, 44, 1876-1885. [CrossRef]

23. Evangelio Araujo, L. Directed Self-Assembly of Block Copolymers on Chemically Nano-Patterned Surfaces. Ph.D. Thesis, Universitat Autònoma de Barcelona, Barcelona, Spain, 2017.

24. Ruiz, R.; Kang, H.; Detcheverry, F.A.; Dobisz, E.; Kercher, D.S.; Albrecht, T.R.; de Pablo, J.J.; Nealey, P.F. Density Multiplication and Improved Lithography by Directed Block Copolymer Assembly. Science 2008, 321, 936-939. [CrossRef] [PubMed]

25. Garner, G.; Williamson, L.; Seidel, R.; Rincon Delgadillo, P.; Hur, S.-M.; Gronheid, R.; Nealey, P.F.; de Pablo, J.J. The effects of geometry and chemistry of nanopatterned substrates on the directed self-assembly of block-copolymer melts. Proc. SPIE 2015, 9423, 1-9. [CrossRef]

26. Evangelio, L.; Fernández-Regúlez, M.; Fraxedas, J.; Müller, M.; Pérez-Murano, F. Role of Penetrability into a Brush-Coated Surface in Directed Self-Assembly of Block Copolymers. ACS Appl. Mater. Interfaces 2018, 11, 3571-3581. [CrossRef]

27. Thomas, E.L.; Anderson, D.M.; Henkee, C.S.; Hoffman, D. Periodic area-minimizing surfaces in block copolymers. Nature 1988, 334, 598-601. [CrossRef]

28. Burgaz, E.; Gido, S.P. T-Junction Grain Boundaries in Block Copolymer-Homopolymer Blends. Macromolecules 2000, 33, 8739-8745. [CrossRef]

29. Jinnai, H.; Sawa, K.; Nishi, T. Direct observation of twisted grain boundary in a block copolymer lamellar nanostructure. Macromolecules 2006, 39, 5815-5819. [CrossRef]

30. Ryu, H.J.; Fortner, D.B.; Lee, S.; Ferebee, R.; De Graef, M.; Misichronis, K.; Avgeropoulos, A.; Bockstaller, M.R. Role of grain boundary defects during grain coarsening of lamellar block copolymers. Macromolecules 2013, 46, 204-215. [CrossRef]

31. Gido, S.P.; Thomas, E.L. Lamellar Diblock Copolymer Grain Boundary Morphology. 2. Scherk Twist Boundary Energy Calculations. Macromolecules 1994, 27, 849-861. [CrossRef] 
32. Gido, S.P.; Thomas, E.L. Lamellar Diblock Copolymer Grain Boundary Morphology. 3. Helicoid Section Twist Boundary Energy. Macromolecules 1997, 30, 3739-3746. [CrossRef]

33. Gido, S.P.; Thomas, E.L. Lamellar Diblock Copolymer Grain Boundary Morphology. 4. Tilt Boundaries. Macromolecules 1994, 27, 6137-6144. [CrossRef]

34. Gido, S.P.; Gunther, J.; Thomas, E.L.; Hoffman, D. Lamellar diblock copolymer grain boundary morphology. 1. Twist boundary characterization. Macromolecules 1993, 26, 4506-4520. [CrossRef]

35. Liu, G.; Ramirez-Hernandez, A.; Yoshida, H.; Nygard, K.; Satapathy, D.K.; Bunk, O.; de Pablo, J.; Nealey, P.F. Morphology of Lamellae-Forming Block Copolymer Films between Two Orthogonal Chemically Nanopatterned Striped Surfaces. Phys. Rev. Lett. 2012, 108, 65502. [CrossRef]

36. Jeong, S.J.; Moon, H.S.; Shin, J.; Kim, B.H.; Shin, D.O.; Kim, J.Y.; Lee, Y.H.; Kim, J.U.; Kim, S.O. One-dimensional metal nanowire assembly via block copolymer soft graphoepitaxy. Nano Lett. 2010, 10, 3500-3505. [CrossRef]

37. Raybin, J.; Ren, J.; Chen, X.; Gronheid, R.; Nealey, P.F.; Sibener, S.J. Real-Time Atomic Force Microscopy Imaging of Block Copolymer Directed Self Assembly. Nano Lett. 2017, 17, 7717-7723. [CrossRef]

38. Oria, L.; Ruiz de Luzuriaga, A.; Alduncín, J.A.; Pérez-Murano, F. Block co-polymer guided self-assembly by surface chemical modification: Optimization of multiple patterning process and pattern transfer. Proc. SPIE 2012, 8323, 832327. [CrossRef]

39. Duque, D.; Katsov, K.; Schick, M. Theory of T junctions and symmetric tilt grain boundaries in pure and mixed polymer systems. J. Chem. Phys. 2002, 117, 10315-10320. [CrossRef]

40. Stoykovich, M.P.; Muller, M.; Kim, S.O.; Solak, H.H.; Edwards, E.W.; de Pablo, J.J.; Nealey, P.F. Directed assembly of block copolymer blends into nonregular device-oriented structures. Science 2005, 308, 1442-1446. [CrossRef]

41. Murphy, J.N.; Harris, K.D.; Buriak, J.M. Automated defect and correlation length analysis of block copolymer thin film nanopatterns. PLoS ONE 2015, 10, e0133088. [CrossRef]

42. Lorenzoni, M.; Evangelio, L.; Nicolet, C.; Navarro, C.; San Paulo, A.; Perez Murano, F. Nanomechanical properties of solvent cast PS and PMMA polymer blends and block co-polymers. J. Micro/Nanolith. MEMS MOEMS 2015, 14, 033509-1-033509-6. [CrossRef]

43. Solid Surface Energy Data (SFE) for Common Polymers. Available online: www.surface-tension.de/solidsurface-energy.htm (accessed on 4 January 2020).

44. Perego, M.; Ferrarese Lupi, F.; Ceresoli, M.; Giammaria, T.J.; Seguini, G.; Enrico, E.; Boarino, L.; Antonioli, D.; Gianotti, V.; Sparnacci, K.; et al. Ordering dynamics in symmetric PS-b-PMMA diblock copolymer thin films during rapid thermal processing. J. Mater. Chem. C 2014, 2, 6655-6664. [CrossRef]

45. Choi, J.; Gunkel, I.; Li, Y.; Sun, Z.; Liu, F.; Kim, H.; Carter, K.R.; Russell, T.P. Macroscopically ordered hexagonal arrays by directed self-assembly of block copolymers with minimal topographic patterns. Nanoscale 2017, 9 , 14888-14896. [CrossRef] [PubMed]

46. Chastek, T.Q.; Lodge, T.P. Grain shapes and growth kinetics during self-assembly of block copolymers. J. Polym. Sci. Part B Polym. Phys. 2006, 44, 481-491. [CrossRef]

47. Wang, X.; Chintapalli, M.; Newstein, M.C.; Balsara, N.P.; Garetz, B.A. Characterization of a Block Copolymer with a Wide Distribution of Grain Sizes. Macromolecules 2016, 49, 8198-8208. [CrossRef]

48. Smilgies, D.M. Scherrer grain-size analysis adapted to grazing-incidence scattering with area detectors. J. Appl. Crystallogr. 2009, 42, 1030-1034. [CrossRef]

49. Limary, R.; Green, P.F. Late-stage coarsening of an unstable structured liquid film. Phys. Rev. E 2002, 66, 021601. [CrossRef]

50. Ceresoli, M.; Volpe, F.G.; Seguini, G.; Antonioli, D.; Gianotti, V.; Sparnacci, K.; Laus, M.; Perego, M. Scaling of correlation length in lamellae forming PS-b-PMMA thin films upon high temperature rapid thermal treatments. J. Mater. Chem. C 2015, 3, 8618-8624. [CrossRef]

51. Ruiz, R.; Bosworth, J.K.; Black, C.T. Effect of structural anisotropy on the coarsening kinetics of diblock copolymer striped patterns. Phys. Rev. B Condens. Matter Mater. Phys. 2008, 77, 054204. [CrossRef]

52. Li, W.; Nealey, P.F.; De Pablo, J.J.; Müller, M. Defect removal in the course of directed self-assembly is facilitated in the vicinity of the order-disorder transition. Phys. Rev. Lett. 2014, 113, 168301. [CrossRef]

53. Hexemer, A.; Stein, G.E.; Kramer, E.J.; Magonov, S. Block copolymer monolayer structure measured with scanning force microscopy moiré patterns. Macromolecules 2005, 38, 7083-7089. [CrossRef]

54. Satake, M.; Iwase, T.; Kurihara, M.; Negishi, N.; Tada, Y.; Yoshida, H. Characteristics of selective PMMA etching for forming a PS mask. Proc. SPIE 2013, 8685, T1-T7. [CrossRef] 
55. Buffet, A.; Rothkirch, A.; Döhrmann, R.; Körstgens, V.; Abul Kashem, M.M.; Perlich, J.; Herzog, G.; Schwartzkopf, M.; Gehrke, R.; Müller-Buschbaum, P.; et al. P03, the microfocus and nanofocus X-ray scattering (MiNaXS) beamline of the PETRA III storage ring: The microfocus endstation. J. Synchrotron Radiat. 2012, 19, 647-653. [CrossRef] [PubMed]

56. Helfand, E.; Wasserman, Z.R. Block Copolymer Theory. 4. Narrow Interphase Approximation. Macromolecules 1976, 9, 879-888. [CrossRef]

57. Carvalho, B.L.; Thomas, E.L. Morphology of Steps in Terraced Block Copolymer Films. Phys. Rev. Lett. 1994, 73, 3321-3324. [CrossRef] [PubMed]

58. Oria, L.; Ruiz De Luzuriaga, A.; Alduncin, J.A.; Perez-Murano, F. Polystyrene as a brush layer for directed self-assembly of block co-polymers. Microelectron. Eng. 2013, 110, 234-240. [CrossRef]

59. Listak, J.; Bockstaller, M.R. Stabilization of grain boundary morphologies in lamellar block copolymer/nanoparticle blends. Macromolecules 2006, 39, 5820-5825. [CrossRef]

60. Stoykovich, M.P.; Kang, H.; Daoulas, K.C.; Liu, G.; Liu, C.C.; De Pablo, J.J.; Müller, M.; Nealey, P.F. Directed self-assembly of block copolymers for nanolithography: Fabrication of isolated features and essential integrated circuit geometries. ACS Nano 2007, 1, 168-175. [CrossRef]

(C) 2020 by the authors. Licensee MDPI, Basel, Switzerland. This article is an open access article distributed under the terms and conditions of the Creative Commons Attribution (CC BY) license (http://creativecommons.org/licenses/by/4.0/). 